\title{
Demographic diversity of TDS foods across Europe
}

\author{
N. F. C. Devlin ${ }^{1}$, B. A. McNulty ${ }^{1}$, A. Turrini ${ }^{2}$, C. Tlustos ${ }^{3}$, A. P. Hearty ${ }^{1}$, J. L. Volatier ${ }^{4}$, \\ C. C. Kelleher ${ }^{1}$ and A. P. Nugent ${ }^{1}$ \\ ${ }^{1}$ UCD Institute of Food and Health, University College Dublin, Ireland, ${ }^{2}$ INRAN, National Research Institute on Food and \\ Nutrition, Rome, Italy, ${ }^{3}$ Food Safety Authority of Ireland, Ireland and ${ }^{4}$ ANSES, France
}

Although no specific guidelines exist, it is recommended that foods selected for total diet studies (TDS) represent $80-95 \%$ of the population's diet ${ }^{(1)}$. Typically, the first step involves analysing population food intakes. The selected foods are then grouped into food groups for further sampling and analysis. The aim of this study was to investigate the demographic diversity of TDS food groups using data from the EFSA Comprehensive Database ${ }^{(2)}$, which was developed from national food consumption surveys and represents 7 population groups for 22 European countries. The percentage contribution of these food groups to the diet are presented for each population group. TDS food selection (prior to food grouping) was based on $90 \%$ of the weight of food consumed and a consumer rate $\geqslant 5 \%$.

\begin{tabular}{|c|c|c|c|c|c|c|c|}
\hline \multirow{2}{*}{$\frac{\text { Population groups* }}{\text { Food groups }}$} & Infants & Toddlers & Children & Teens & Adults & Elderly & Very Elderly \\
\hline & \multicolumn{7}{|c|}{ Percentage contribution of TDS foods per food group to the overall diet Weighted Mean } \\
\hline Grains \& grain products & 2.4 & 5.4 & 8.9 & 9.3 & 6.3 & 5.9 & 7.2 \\
\hline Vegetable \& vegetable products & 1.5 & 3.8 & 3.0 & 2.9 & 3.4 & 3.7 & 4.1 \\
\hline Starchy roots \& tubers & 1.7 & 3.8 & 4.2 & 4.0 & 2.6 & 3.2 & 4.1 \\
\hline Legumes, nuts \& oils eeds & - & 0.1 & 0.2 & 0.4 & 0.5 & 0.2 & 0.2 \\
\hline Fruits \& fruit products & 2.0 & 5.3 & 5.8 & 3.9 & 4.1 & 6.4 & 7.3 \\
\hline Meat \& meat products & 0.8 & 2.7 & 3.5 & 4.3 & 3.3 & 2.7 & 3.1 \\
\hline Fish \& other seafood & - & 0.1 & 0.4 & 0.4 & 0.2 & 0.4 & 0.4 \\
\hline Milk \& dairy products & 17.8 & 23.3 & 25.2 & 13.7 & 7.0 & 6.5 & 6.0 \\
\hline Eggs \& egg products & - & 0.4 & 0.5 & 0.3 & 0.5 & 0.4 & 0.4 \\
\hline Sugar \& confectionary & 1.1 & 0.8 & 1.0 & 0.8 & 0.4 & 0.3 & 0.4 \\
\hline Fats \& oils & 0.4 & 0.7 & 0.9 & 0.6 & 0.7 & 0.9 & 1.2 \\
\hline Fruit $\&$ vegetable juices & 2.9 & 6.1 & 7.8 & 5.7 & 3.3 & 2.5 & 1.5 \\
\hline Non-alcoholic beverages & 3.4 & 2.7 & 8.1 & 13.4 & 21.1 & 21.9 & 20.3 \\
\hline Alcoholic beverages & - & - & - & 0.7 & 6.5 & 5.6 & 4.7 \\
\hline Drinking water & 49.7 & 27.0 & 18.0 & 23.1 & 26.0 & 25.1 & 22.4 \\
\hline Herbs/spices \& condiments & - & 0.01 & 0.4 & 0.6 & 0.4 & 0.2 & 0.3 \\
\hline Food for infants \& children & 12.7 & 5.2 & 0.1 & & - & - & - \\
\hline Nutritional products & - & - & - & & - & - & - \\
\hline Composite food & 0.03 & 0.5 & 5.1 & 3.5 & 1.5 & 1.6 & 3.7 \\
\hline Desserts \& other foods & - & 0.9 & 1.7 & 0.9 & 0.3 & 0.3 & 0.4 \\
\hline Totals & 96.4 & 88.8 & 94.8 & 88.5 & 88.1 & 87.8 & 87.7 \\
\hline
\end{tabular}

*Availability of surveys varied across countries $(n)$ : Infants 2; Toddlers 7; Children 13; Teens: 10; Adults; Elderly 7; Very Elderly 6.

Using this approach, the percentage $(\%)$ contribution to the diet differed appreciably for almost all food groups for infants in comparison to the other population groups. Individual food group contribution varied across population groups, with milk and dairy products contributing more to the younger age groups, while drinking water was the greatest \% contributor to the diet across all groups apart from children. This research shows that while TDS may account for $80-95 \%$ of the diet, demographic diversity exists regarding food groups and should be taken into account when planning a TDS food list.

The research leading to these results received funding from the European Union 7th Framework Programme (FP7/2007-2013) under Grant Agreement 289108 (Total Diet Study Exposure). This publication reflects only the authors' views, and the Community is not liable for any use made of the information contained therein.

1. EFSA, FAO and WHO (2011) EFSA Journal; 9(11): 2450

2. EFSA Comprehensive European Food Consumption Database (2011) European Food Safety Authority. 